\title{
The effects of a supervised Pilates training program on balance in Parkinson's disease
}

\author{
Liam Johnson $^{1,2}$, David Putrino ${ }^{1}$, lan James $^{3}$, Julian Rodrigues ${ }^{1}$, Rick Stell ${ }^{1}$, \\ Gary Thickbroom ${ }^{1}$, Frank L. Mastaglia ${ }^{1^{*}}$ \\ ${ }^{1}$ Australian Neuro-Muscular Research Institute, Movement Disorders Clinic, Queen Elizabeth II Medical Centre, Centre for Neuro- \\ muscular \& Neurological Disorders, University of Western Australia, Crawley, Australia; \\ *Corresponding Author: francis.mastaglia@anri.uwa.edu.au \\ ${ }^{2}$ School of Psychological and Clinical Sciences, Charles Darwin University, Darwin, Australia \\ ${ }^{3}$ Department of Mathematics and Statistics, Murdoch University, Murdoch, Australia
}

Received 7 November 2012; revised 6 January 2013; accepted 16 January 2013

Copyright (c) 2013 Liam Johnson et al. This is an open access article distributed under the Creative Commons Attribution License, which permits unrestricted use, distribution, and reproduction in any medium, provided the original work is properly cited.

\begin{abstract}
Pilates therapy improves core muscle function and axial stability but its effects on balance in idiopathic Parkinson's disease (IPD) have not been evaluated. The objective of this study was to evaluate the effects of a Pilates exercise program on postural stability and balance confidence in people with IPD. Ten IPD patients (Hoehn \& Yahr Stage 1-3) with a history of falls or nearfalls had the following assessments before and after completion of a 6-week supervised Pilates exercise program: Activities-Specific Balance Confidence Scale (ABC); Berg Balance Scale (BBS); Schwab and England Scale (SES); Unified Parkinson's Disease Rating Scale (UPDRS); pull-test; timed-up-and-go (TUG); 5-metre walk; static and dynamic posturography. There were significant improvements in BBS score, 5-metre walk time and TUG after the training program, as well as improvement trends in some posturographic measures. Participants also reported improved balance confidence with Activities of Daily Living (ADLs). Our findings suggest that Pilates therapy can be beneficial in IPD and warrants further evaluation in a larger study.
\end{abstract}

Keywords: Parkinson's Disease; Pilates; Postural Instability; Static; Dynamic Posturography

\section{INTRODUCTION}

Postural instability (PI) and falls are a major problem in idiopathic Parkinson's disease (IPD) and are poorly responsive to dopaminergic medications [1-3]. The cau- ses of PI are multifactorial and include axial rigidity, bradykinesia, freezing, impaired sensorimotor integration and cognitive function [4-7]. One of the factors contributing to PI is reduced truncal flexibility due to axial rigidity, which tends to worsen as the disease progresses [8, 9]. Pilates is a type of exercise therapy that aims to improve flexibility and axial stability by strengthening the core musculature of the body and is based on the performance of coordinated movement sequences rather than simple repetitive movements as in other exercise programs $[10,11]$. Pilates has been shown to improve balance in elderly individuals [12-16], but its impact on postural stability in IPD has not been evaluated.

We investigated the effects of a 6-week Pilates training program on postural stability, balance confidence and ADLs in a group of patients with IPD with a history of falls or near-falls.

\section{PATIENTS AND METHODS}

Ten individuals who fulfilled the UK Brain Bank criteria for IPD [17] were recruited from the Movement Disorders Clinics at the Australian Neuro-Muscular Research Institute. Demographic details are given in Table 1. Participants were included if they met the following criteria: A proven diagnosis of IPD; were on a stable drug regimen; had a prior history of one or more falls and/or near-falls in the preceding two years; and were not receiving any other physical therapy or performing any other regular exercise activities. Participants were excluded if the disease was too advanced (Hoehn \& Yahr > 3 ); experienced severe dyskinesias and/or motor fluctuations; had previously been diagnosed with stroke or dementia; and if they had any other medical conditions or physical disabilities interfering with their mobility. All 
participants were given a clear description of the training program and objectives of the study and gave informed consent before entering the study. The study was approved by the Human Research Ethics Committee of the Queen Elizabeth II Medical Centre.

The 6-week program consisted of twice weekly one hour training sessions by a qualified Pilates instructor (DP) and an assistant (LJ), when participants were in their best ON-state. The program focused on reducing axial stiffness and improving trunk flexibility, and consisted of a combination of plinth exercises, gym-ball exercises (75 cm and $55 \mathrm{~cm}$ anti-burst gym balls), stepping exercises (24 cm and $11 \mathrm{~cm}$ steps), and exercises on a Pilates reformer. The actual combination and duration of individual exercises for each participant was based on a preliminary assessment of their functional capabilities, strength and degree of flexibility. The degree of difficulty of the exercises was increased progressively during the 6-week period, based upon performance and subjective feedback from the participant. The participants were closely monitored for any adverse effects, and progressions involved the addition of movements to increase task complexity, reducing the base of support, and increasing the resistance during the reformer exercises.

The following assessments were performed prior to and following completion of the 6-week program: 1) Hoehn and Yahr staging [18]; 2) Schwab and England Scale (SES) [19]; 3) Activities-Specific Balance Confidence Scale (ABC) [20]; 4) Berg Balance Scale (BBS) [21]; 5) Unified Parkinson's Disease Rating Scale (UPDRS) axial, tremor and motor subscores [19]; 6) Romberg test [22]; 7) Pull-test [23]; 8) Timed Up-and-Go (TUG) test [24]; 9) A 5-metre walk, in which the participants were instructed to walk 5 metres at a comfortable pace and the duration (seconds), step count and cadence were recorded; 10) Static and dynamic posturography was performed using a stable force platform (AccuSway Plus, Advanced Mechanical Technology, Inc.) as described previously [25].

Replicate measurements were averaged where applicable. Paired t-tests were utilized to compare before and after Pilates training scores and effects of age and disease duration on the score differences were assessed by linear regressions. Significance was set at the $\mathrm{p}<0.05$ level. All data were included in analyses apart from single cases in each of the static and dynamic posturography categories which were large outliers. All values reported are group averages and standard errors unless otherwise indicated.

\section{RESULTS}

All participants completed the program without any adverse effects and were able to progress at varied rates to more complex and difficult exercise combinations over the 6-week period. At the completion of the program, all reported feeling subjectively stronger, more mobile and more confident in activities of daily living, although there was no change in SES scores. None experienced any falls during the 6-week program.

As shown in Table 2, there was a significant improvement in the BBS score following the training period, which was greater for the older ages $(p=0.023)$, and there was also a marginal improvement in balance confidence (ABC scale). There was a significant improvement in the 5-metre walk duration ( $p=0.03)$, with an increase in cadence (number of steps per minute) ( $\mathrm{p}=$ 0.095). The duration of the TUG test did not change but there was a significant reduction in cadence $(p=0.037)$. Dynamic posturography showed improvement trends in reaction time and velocity and an increase in static sway path area after the training program, although the changes were not statistically significant (Table 2).

\section{DISCUSSION}

This preliminary study has shown that a 6-week Pilates exercise program is beneficial to IPD patients who are prone to falls, and resulted in significant improvements in their balance and mobility and greater confidence with ADLs. The observation of a significant change in the BBS is particularly important as the 14 items of the BBS represent tasks that are common to daily life [21] and impairments in some of these tasks may play a key role in fall events through loss of balance (e.g. reaching while outstretched, turning to look behind, bending over to pick up an object). The improvement in the BBS is therefore positive evidence of improved functional balance ability and capacity to perform everyday activities. In addition, there was an improvement in walking speed and step cadence in the 5-metre walk test.

Although the changes in posturographic measures at the end of the training period were not significant, a number of trends may be of functional relevance. Firstly, the increase in the static sway path area suggests an improvement in trunk flexibility which could also account for the increased degree of target overshoot in the dynamic posturography. In addition, the trends towards improvement in reaction time and velocity in the dynamic posturography may reflect an improved capacity to respond to alterations in the centre of gravity. This suggests that Pilates may improve the capacity of the individual to respond to physical perturbations that might otherwise result in falls during every-day life.

Although the present study was uncontrolled, the findings suggest that Pilates therapy can be beneficial in IPD patients with PI. Further investigation in larger pa- tient groups is required to confirm our findings and to determine whether Pilates is more effective than other exercise programs for improving balance and reducing falls risk in IPD. 
Table 1. Participant demographics.

\begin{tabular}{cccccc}
\hline Participant & Gender & Age & Disease Duration (years) & Hoehn and Yahr Score & Medications \\
\hline 1 & Male & 54 & 9 & 3 & Madopar, Sinemet, Cabergoline \\
2 & Male & 72 & 7 & 3 & Madopar, Repreve \\
3 & Male & 64 & 10 & 2 & Madopar, Repreve \\
4 & Male & 63 & 14 & 2 & Sinemet \\
5 & Female & 76 & 13 & 2.5 & Sinemet, Stalevo \\
6 & Male & 77 & 2 & 2 & Madopar \\
7 & Male & 70 & 3 & 3 & Madopar, Eldepryl \\
8 & Male & 70 & 4 & 1 & Madopar, Pramipexole \\
9 & Female & 53 & 5 & 3 & Madopar Pramipexole \\
10 & Female & 77 & $7.3 \pm 4.1$ & $2.4 \pm 0.6$ & Madopar \\
\hline
\end{tabular}

Table 2. Results of clinical, functional and posturographic assessments before and after training.

\begin{tabular}{|c|c|c|c|}
\hline & Pre-Training & Post-Training & p-Value \\
\hline \multicolumn{4}{|l|}{ Clinical Assessment } \\
\hline BBS & $47.1 \pm 2.0$ & $50.4 \pm 1.5$ & $0.023^{*}$ \\
\hline $\mathrm{ABC}(\%)$ & $71.0 \pm 3.4$ & $74.7 \pm 3.9$ & 0.331 \\
\hline SES (\%) & $79 \pm 3.8$ & $80 \pm 2.1$ & 0.823 \\
\hline UPDRS Motor Score & $19.1 \pm 3.1$ & $18.1 \pm 3.4$ & 0.727 \\
\hline \multicolumn{4}{|l|}{ Functional Assessments } \\
\hline 5-metre walk (seconds) & $6.3 \pm 0.4$ & $5.5 \pm 0.3$ & $0.030^{*}$ \\
\hline 5-metre walk cadence (steps/minute) & $97.4 \pm 5.2$ & $103.7 \pm 5.3$ & 0.095 \\
\hline TUG cadence (steps/minute) & $84.9 \pm 3.4$ & $78.0 \pm 3.8$ & $0.037^{*}$ \\
\hline TUG (seconds) & $10.1 \pm 0.6$ & $10.2 \pm 0.6$ & 0.750 \\
\hline \multicolumn{4}{|l|}{ Static Posturography } \\
\hline Static sway area $\left(\mathrm{cm}^{2}\right)$ (eyes open) & $2.9 \pm 0.7$ & $3.3 \pm 0.9$ & 0.361 \\
\hline Sway path length (cm)(eyes open) & $108.6 \pm 10.0$ & $108.5 \pm 9.3$ & 0.960 \\
\hline \multicolumn{4}{|l|}{ Dynamic Posturography ${ }^{\#}$} \\
\hline Reaction time (seconds) & $1.14 \pm 0.10$ & $0.96 \pm 0.10$ & 0.172 \\
\hline Velocity (cm/second) & $1.5 \pm 0.2$ & $2.0 \pm 0.3$ & 0.153 \\
\hline Target overshoot (cm) & $0.50 \pm 0.13$ & $0.72 \pm 0.13$ & $0.044^{*}$ \\
\hline
\end{tabular}

"Denotes statistical significance by paired, two-tailed T-test with $\mathrm{p}<0.05$; ${ }^{*}$ One case omitted due to outlying values.

\section{ACKNOWLEDGEMENTS}

We thank the Parkinson's patients who participated in the study and Professor Norman Palmer for his helpful advice. Liam Johnson was a recipient of an Australian Postgraduate Award from the University of Western Australia. The Neuromuscular Foundation of Western Australia provided support for the study.

\section{REFERENCES}

[1] Boonstra, T.A., van der Kooij, H., Munneke, M. and Bloem B.R. (2008) Gait disorders and balance disturbances in Parkinson's disease: Clinical update and pathophysiology. Current Opinion in Neurology, 21, 461-471. doi:10.1097/WCO.0b013e328305bdaf 
[2] Pickering, R.M., Grimbergen, Y.A., Rigney, U., et al. (2007) A meta-analysis of six prospective studies of falling in Parkinson's disease. Movement Disorders, 22, 18921900. doi: $10.1002 / \mathrm{mds} .21598$

[3] Shulman, L.M., Gruber-Baldini, A.L., Anderson, K.E., et al. (2008) The evolution of disability in Parkinson's disease. Movement Disorders, 23, 790-796. doi:10.1002/mds.21879

[4] Bloem, B.R. (1992) Postural instability in Parkinson's disease. Clinical Neurology and Neurosurgery, 94, S41-45. doi:10.1016/0303-8467(92)90018-X

[5] Bronte-Stewart, H.M., Minn, A.Y., Rodrigues, K., Buckley, E.L. and Nashner, L.M. (2002) Postural instability in idiopathic Parkinson's disease: The role of medication and unilateral pallidotomy. Brain, 125, 2100-2114. doi:10.1093/brain/awf207

[6] Gray, P. and Hildebrand, K. (2000) Fall risk factors in Parkinson's disease. Journal of Neuroscience Nursing, 32, 222-228. doi:10.1097/01376517-200008000-00006

[7] Nallegowda, M., Singh, U., Handa, G., et al. (2004) Role of sensory input and muscle strength in maintenance of balance, gait, and posture in Parkinson's disease: A pilot study. American Journal of Physical Medicine and Rehabilitation, 83, 898-908. doi:10.1097/01.PHM.0000146505.18244.43

[8] Horak, F.B., Dimitrova, D. and Nutt, J.G. (2005) Direction-specific postural instability in subjects with Parkinson's disease. Experimental Neurology, 193, 504-521. doi:10.1016/j.expneurol.2004.12.008

[9] Visser, J.E., Allum, J.H., Carpenter, M.G., et al. (2008) Effect of subthalamic nucleus deep brain stimulation on axial motor control and protective arm responses in Parkinson's disease. Neuroscience, 157, 798-812. doi:10.1016/j.neuroscience.2008.09.051

[10] Kloubec, J.A. (2010) Pilates for improvement of muscle endurance, flexibility, balance, and posture. Journal of Strength and Conditioning Research, 24, 661-667. doi:10.1519/JSC.0b013e3181c277a6

[11] Emery, K., De Serres, S.J., McMillan, A. and Côté, J.N. (2010) The effects of a pilates training program on armtrunk posture and movement. Clinical Biomechanics, 25, 124-130. doi:10.1016/j.clinbiomech.2009.10.003

[12] Kaesler, D.S., Mellifont, R.B., Swete Kelly, P. and Taafe, D.R. (2007) A novel balance exercise program for postural stability in older adults: A pilot study. Journal of Bodywork and Movement Therapies, 11, 37-43. doi:10.1016/j.jbmt.2006.05.003

[13] Siqueira Rodrigues, B.G., Ali Cader, S., Bento Torres, N.V., Oliveira, E.M. and Martin Dantas, E.H. (2010) Pilates method in personal autonomy, static balance and quality of life of elderly females. Journal of Bodywork and Movement Therapies, 14, 195-202. doi:10.1016/j.jbmt.2009.12.005

[14] Newell, D., Shead, V. and Sloane, L. (2012) Changes in gait and balance parameters in elderly subjects attending an 8-week supervised pilates programme. Journal of Bodywork and Movement Therapies, 16, 549-554. doi:10.1016/j.jbmt.2012.02.002

[15] Bird, M.-L., Hill, K.D. and Fell, J.W. (2012) A randomized controlled study investigating static and dynamic balance in older adults after training with pilates. Archives of Physical Medicine and Rehabilitation, 93, 43-49. doi:10.1016/j.apmr.2011.08.005

[16] Hall, D.W., Nichols, J., Aguilar, L. and Larkam, E. (1999) Effects of pilates-based-training on static and dynamic balance in an elderly population. Medicine and Science in Sport and Exercise, 31, S388. doi:10.1097/00005768-199905001-01987

[17] Hughes, A.J., Daniel, S.E., Kilford, L. and Lees, A.J. (1992) Accuracy of clinical diagnosis of idiopathic Parkinson's disease: A clinic-pathological study of 100 cases. Journal of Neurology, Neurosurgery and Psychiatry, 55, 181-184. doi:10.1136/jnnp.55.3.181

[18] Hoehn, M.M. and Yahr, M.D. (1967) Parkinsonism: Onset, Progression and mortality. Neurology, 17, 427-442. doi:10.1212/WNL.17.5.427

[19] Martínez-Martín, P., Gil-Nagel, A., Gracia, L.M., Gómez, J.B., Martínez-Sarriés, J., Bermejo, F. and The Cooperative Multicentric Group (1994) Unified Parkinson's disease rating scale characteristics and structure. Movement Disorders, 9, 76-83. doi:10.1002/mds.870090112

[20] Adkin, A.L., Frank, J.S. and Jog, M.S. (2003) Fear of falling and postural control in Parkinson's disease. Movement Disorders, 18, 496-502. doi:10.1002/mds.10396

[21] Berg, K.O., Maki, B.E., Williams, J.L., Holliday, P.J. and Wood-Dauphinee, S.L. (1992) Clinical and laboratory measures of postural balance in an elderly population. Archives of Physical Medicine and Rehabilitation, 73, 10731080.

[22] Smithson, F., Morris, M.E. and Iansek, R. (1998) Performance on clinical tests of balance in Parkinson's disease. Physical Therapy, 78, 577-592.

[23] Visser, M., Marinus, J., Bloem, B.R., Kisjes, H., van den Berg, B.M. and van Hilten, J.J. (2003) Clinical tests for the evaluation of postural instability in patients with Parkinson's disease. Archives of Physical Medicine and Rehabilitation, 84, 1669-1674. doi:10.1053/S0003-9993(03)00348-4

[24] Morris, S., Morris, M.E. and Iansek, R. (2001) Reliability of measurement obtained with the timed “up \& go" test in people with Parkinson disease. Physical Therapy, 81, 810818.

[25] Johnson, L., James, I., Rodrigues, J., Stell, R., Thickbroom, G. and Mastaglia, F.L. (2013) Clinical and posturographic correlates of falling in a Parkinson's disease cohort. Movement Disorders, in Press. doi:10.1002/mds.25449 